\title{
Acessibilidade em universidades públicas: estudo de caso de uma biblioteca.
}

\author{
Raphaela Banks ${ }^{1 ;}$ \\ Bruno Barros ${ }^{2}$; \\ Gael Araújo ${ }^{3}$.
}

resumo:

A difusão de universidades públicas no Brasil aliada às tecnologias de sistemas pré-moldados da engenharia civil tem tornado possível a rápida construção de centros universitários, incluindo as bibliotecas, podendo levar a problemas de acessibilidade nesses espaços. O artigo analisa a acessibilidade de uma biblioteca recém construída numa universidade pública no interior do Nordeste brasileiro, utilizando a Metodologia Ergonômica para o Ambiente Construído (MEAC). A investigação apontou diversas incoerências no que tange à acessibilidade e alguns outros fatores adicionais, o que tornou possível a elaboração de uma série de recomendações ergonomizadoras direcionadas à biblioteca com foco na acessibilidade de usuários cadeirantes.

palavras-chave:

acessibilidade; biblioteca; universidade federal.

Espaço reservado para organização do congresso.

\footnotetext{
${ }^{1} \mathrm{http}: / /$ lattes.cnpq.br/1515597153281041

${ }^{2}$ http://lattes.cnpq.br/7234637867733181

${ }^{3}$ http://lattes.cnpq.br/id=K2458939D6
} 


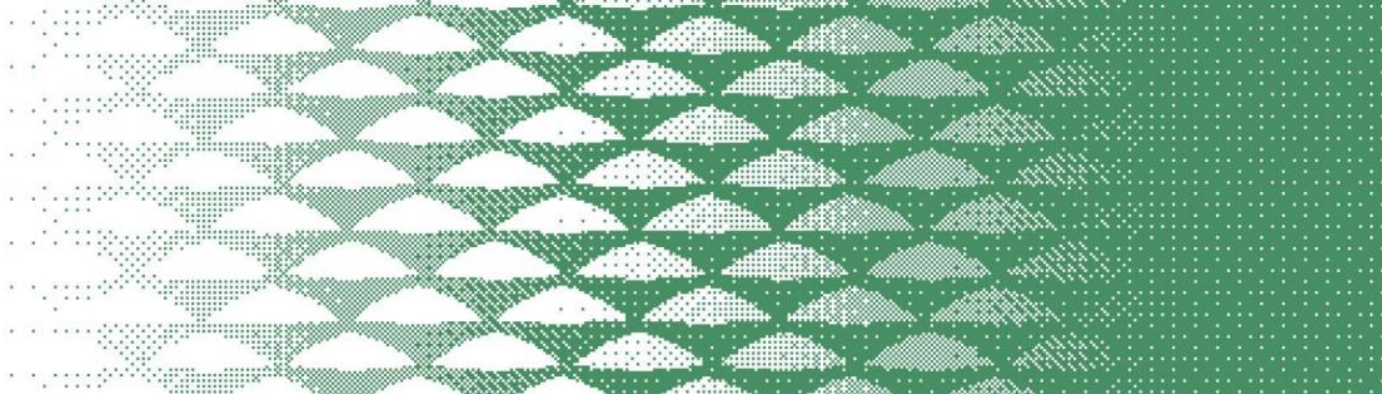

\section{Introdução}

A expansão da rede universitária federal para cidades do interior do país tem proporcionado o acesso à educação superior gratuita a essas populações, sendo possível a edificação de novos prédios de maneira rápida por meio de estruturas pré-moldadas. Contudo, essa agilidade construtiva nem sempre reflete adequações às necessidades, características e limitações dos usuários com mobilidade reduzida e, neste ponto, a Ergonomia surge como forte aliada na abordagem de tais espaços.

O comprometimento da saúde humana em decorrência de espaços físicos inadequados em bibliotecas tem sido tratado em pesquisas na medida em que se acompanha a evolução dos processos construtivos dos seus espaços. Pesquisadores como Mendes e Bergiante (2018); Capri, Dos Santos Bahia e Luiz Pinto (2012); Wellichan e Santos (2017); Erilze (2018); Tassa, Braga e Motter (2018) e Vasconcelos, Villarouco e Soares (2009) têm se debruçado neste tipo de investigação científica. Dentro deste contexto, o presente artigo é resultado da aplicação da Metodologia Ergonômica para o Ambiente Construído (MEAC) no espaço de uma biblioteca recentemente instalada em uma universidade pública de uma cidade do interior do Nordeste brasileiro, com foco na acessibilidade de usuários cadeirantes. A análise realizada teve como objetivo identificar as inadequações presentes no local e pontos passíveis de melhorias, e para tanto, foram realizadas aferições e levantamentos de informações físicas e perceptivas sobre o ambiente. A pesquisa considerou que uma lista de recomendações ergonômicas e uma proposta projetual conceitual baseada nas recomendações tecidas podem contribuir com a promoção da otimização do espaço por parte da instituição de ensino.

\section{Materiais e Métodos}

Para a realização desse trabalho foi adotada a Metodologia Ergonômica para o Ambiente Construído (MEAC). A MEAC é composta por quatro etapas: 1. Análise Física (a qual compreende a Análise Global do Ambiente, a Identificação da Configuração Ambiental e a Avaliação do Ambiente em Uso); 2. Percepção Ambiental do Usuário; 3. Diagnóstico Ergonômico do Ambiente; e 4. Proposições Ergonômicas para o Ambiente (VILLAROUCO, 2007).

A análise Global do Ambiente conduziu a uma interpretação espacial do local e possibilitou uma visão sistêmica a partir do conhecimento dos materiais, dos usuários, dos equipamentos utilizados, fluxos, processos. Na fase de Identificação da Configuração do Ambiente foram identificadas as condições físico-ambientais, do trabalho realizado, tarefas desenvolvidas, características das estações de trabalho e equipamentos. Na fase de Avaliação do Ambiente em Uso no Desempenho das Atividades, avaliou-se a relação entre o corpo humano e as atividades desempenhadas no ambiente. Na fase de Percepção Ambiental fez-se um estudo da percepção que os usuários têm do ambiente, para identificar as características cognitivas e perceptuais. A etapa de Diagnóstico Ergonômico do Ambiente e a de Proposições Ergonômicas para o Ambiente, respectivamente, apresentaram os resultados das avaliações e expuseram recomendações de alterações direcionadas ao ambiente em questão.

\section{Resultados}

Na fase de Análise Global do Ambiente, verificou-se que o espaço da biblioteca tem formato retangular e esteticamente monótono, sem grandes variações cromáticas (cores neutras e frias) ou de texturas, tanto nos elementos arquitetônicos quando no mobiliário, e parece amplo, apesar da ocupação predominante de grandes estantes de livros. Dispõe de uma porta de acesso, do tipo giro, com uma folha em vidro, um vão de acesso aos banheiros e onze janelas basculantes com molduras na cor azul, com vidro transparente e películas adesivas, auxiliando na iluminação diurna e na ventilação do ambiente interno e na visualização do ambiente externo. Pode-se ressaltar negativamente a existência de pilares e fiações elétricas expostas, que atrapalham a circulação e variação do leiaute e oferece risco à segurança, respectivamente (Figura 1). 


\section{JOP 21 DESIGN

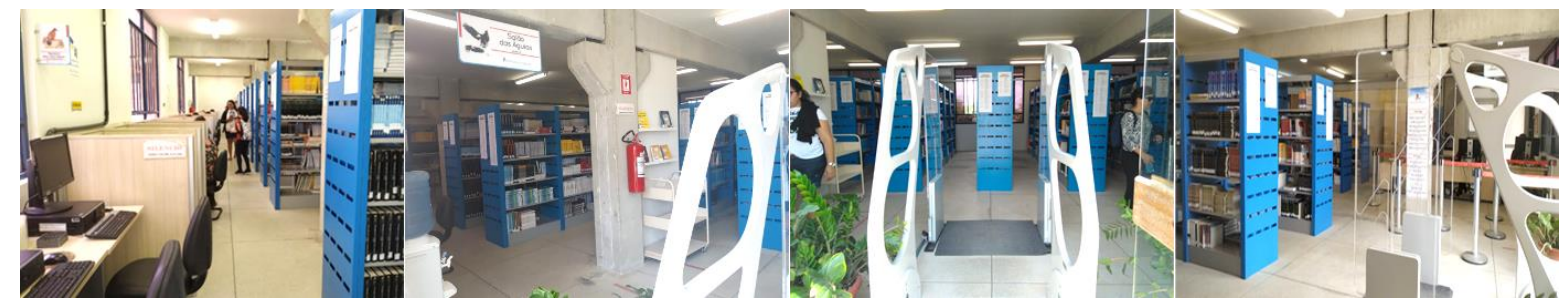

Figura 1 - Visão geral da biblioteca.

Fonte: Os autores (2021)

Com relação à etapa de Identificação da Configuração Ambiental, a biblioteca ocupa uma área de $295,5 \mathrm{~m}^{2}$, com paredes e teto de alvenaria, emassados e pintados na cor branco gelo, com piso em granilite polido na cor cinza. As instalações elétricas são compostas por eletrodutos expostos na cor preta, fixados às paredes e ao piso, havendo ainda, um sistema de sinalização com a temática de aves brasileiras. O espaço é composto por 4 setores (área de estudo, consulta, acervo e atendimento), e o acervo ocupa a maior área, com 2 carrinhos de recolhimento de livros e dezenove estantes de chapa metálica nas cores cinza e azul, com dimensões de $0.58 \mathrm{~m}$ de largura e $2.00 \mathrm{~m}$ de altura (Figura 2).

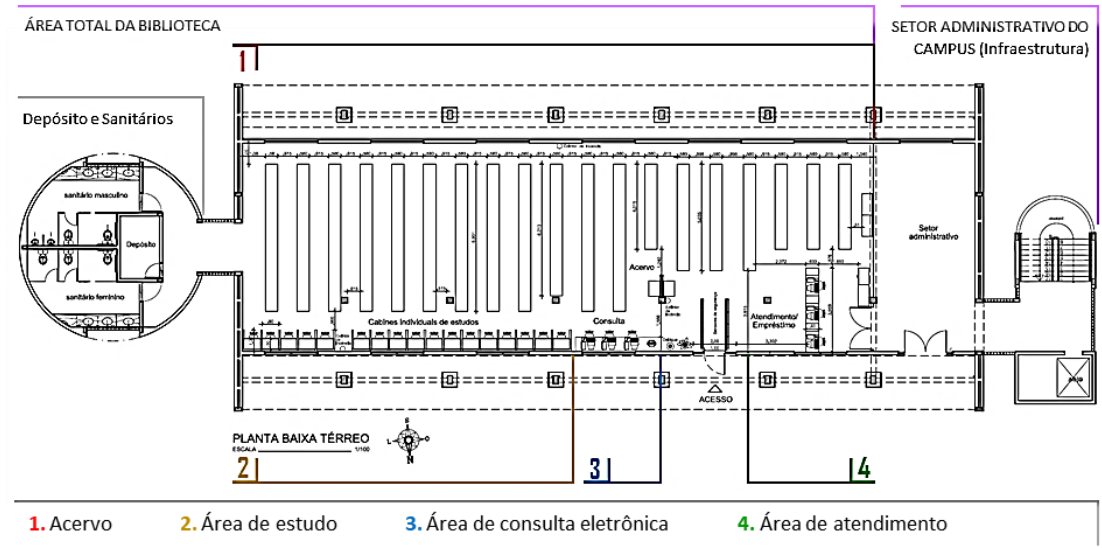

Figura 2 - Planta baixa com leiaute da biblioteca.

Fonte: Os autores (2021)

O setor de estudos encontra-se à esquerda da porta de acesso, composto por 17 cabines individuais de dimensões de $0.80 \mathrm{~m}$ de largura, $0.50 \mathrm{~m}$ de profundidade e $0.75 \mathrm{~m}$ de altura. Há 15 cadeiras estofadas e duas tomadas por cabine, abaixo do tampo e próximas ao piso. Duas destas cabines são sinalizadas para o uso de cadeirantes, e não são acompanhadas por cadeiras. O setor de consulta eletrônica, também à esquerda do acesso, dispõe de 4 mesas e 3 cadeiras com mesma especificação. A área de atendimento, localiza-se à direita da porta de acesso, constituído por 3 mesas, 3 gaveteiros e 1 armário, ambos em MDF revestido por melamina em textura de madeira e 3 cadeiras aos moldes das anteriormente citadas. A biblioteca está próxima às salas de aula, restaurante, parada de ônibus, posto de saúde e lanchonetes, oferecendo recursos de internet e sanitários.

$\mathrm{Na}$ avaliação do Conforto Ambiental, foram estabelecidos três pontos A, B e C para aferição dos níveis de iluminação, ventilação e ruído (Figura 3), foram utilizados aparelhos classificados de conformidade obrigatória recentemente calibrados da marca UNI-T. O ponto A foi situado no local de estudo dos usuários cadeirantes, onde há agrupamento de janelas e projeção de luz natural para o interior; o ponto B foi disposto no acervo; e o ponto C, na interseção entre o acervo e área de atendimento. 

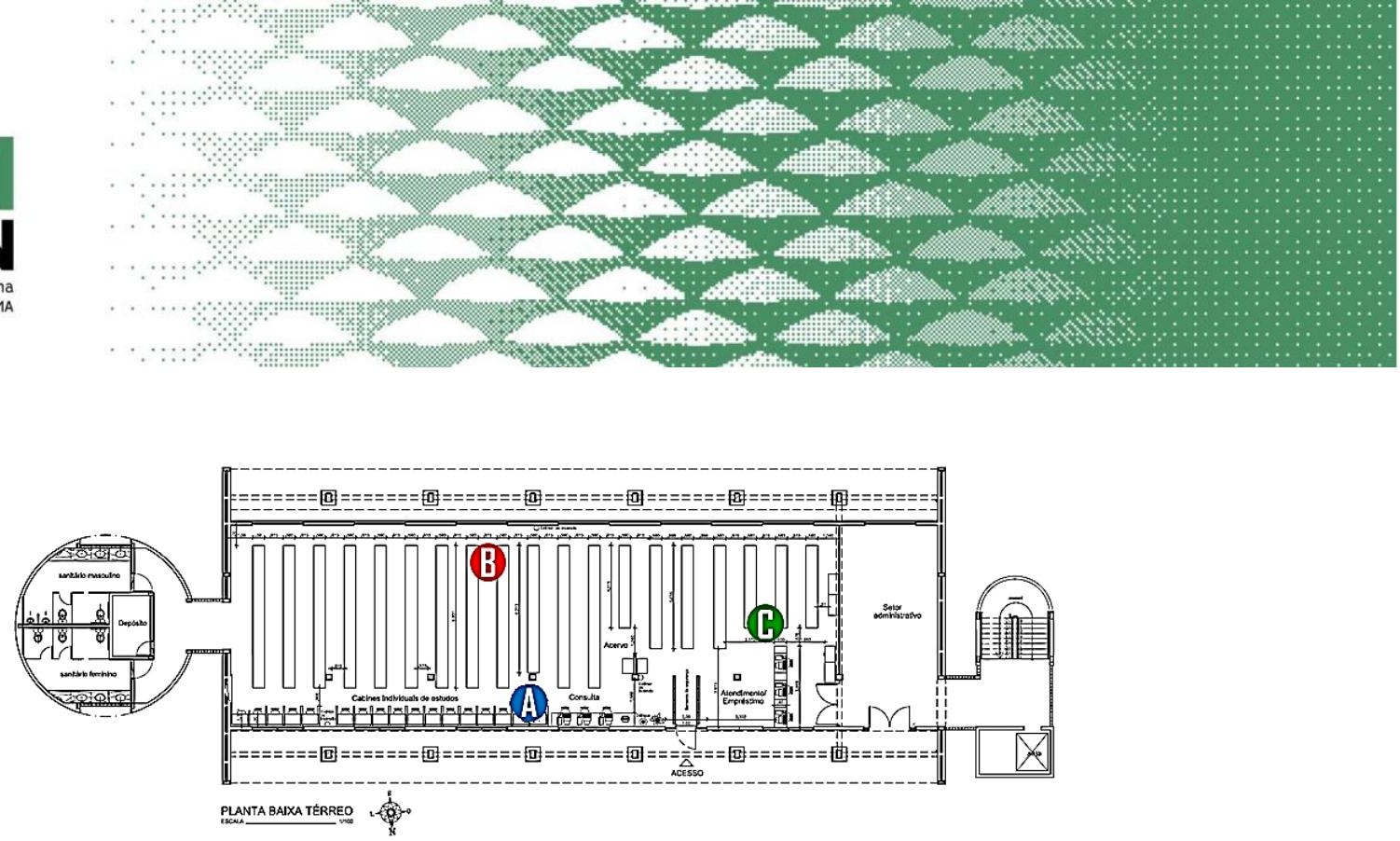

Figura 3 - Pontos de Aferição A, B e C.

Fonte: Os autores (2021)

Para verificação dos níveis de iluminação do ambiente, foi utilizado um Luxímetro. Todos os resultados se mostraram elevados (Tabela 01).

Tabela 1 - Níveis de iluminação do ambiente em lux.

\begin{tabular}{|c|c|c|c|c|c|c|c|}
\hline \multirow[t]{2}{*}{ Local } & \multicolumn{3}{|c|}{ Medição } & \multicolumn{3}{|c|}{ Situação (Adequado - A; Inadequado - I) } & \multirow{2}{*}{$\begin{array}{c}\text { RECOMENDAÇÃO } \\
\text { NHO-11 } \\
\text { Casos comuns: valor do meio }\end{array}$} \\
\hline & Manhã & Tarde & Noite & Manhã & Tarde & Noite & \\
\hline Ponto A & $780 \operatorname{lux}$ & $760 \operatorname{lux}$ & $720 \operatorname{lux}$ & I & I & A & \multirow{3}{*}{$300-500-750 \operatorname{lux}$} \\
\hline Ponto B & $715 \operatorname{lux}$ & $710 \operatorname{lux}$ & $700 \operatorname{lux}$ & A & A & $\mathrm{A}$ & \\
\hline Ponto C & $760 \operatorname{lux}$ & $750 \operatorname{lux}$ & $720 \operatorname{lux}$ & I & A & A & \\
\hline
\end{tabular}

Fonte: Os autores (2021)

Na medição de temperatura foram utilizados um termômetro e um anemômetro. A temperatura se apresentou inadequada em todos os pontos e horários aferidos (Tabela 02).

Tabela 2 - Níveis de temperatura do ambiente em ${ }^{\circ} \mathrm{C}$.

\begin{tabular}{|c|c|c|c|c|c|c|c|}
\hline \multirow[t]{2}{*}{ Local } & \multicolumn{3}{|c|}{ Medição } & \multicolumn{3}{|c|}{ Situação (Adequado - A; Inadequado - I) } & \multirow[t]{2}{*}{$\begin{array}{c}\text { RECOMENDAÇÃO } \\
\text { NR } 17\end{array}$} \\
\hline & Manhã & Tarde & Noite & Manhã & Tarde & Noite & \\
\hline Ponto A & $30^{\circ} \mathrm{C}$ & $29^{\circ} \mathrm{C}$ & $29^{\circ} \mathrm{C}$ & I & I & $\mathrm{I}$ & \multirow{3}{*}{$20^{\circ} \mathrm{C}-23^{\circ} \mathrm{C}$} \\
\hline Ponto B & $29^{\circ} \mathrm{C}$ & $28^{\circ} \mathrm{C}$ & $26^{\circ} \mathrm{C}$ & I & I & A & \\
\hline Ponto C & $30^{\circ} \mathrm{C}$ & $28^{\circ} \mathrm{C}$ & $27^{\circ} \mathrm{C}$ & I & I & A & \\
\hline
\end{tabular}

Para medição do ruído, utilizou-se um decibelímetro e, nos três horários de funcionamento, os níveis de ruído presentes na biblioteca ultrapassam as recomendações (Tabela 03).

Tabela 3 - Níveis de ruído do ambiente em decibéis $(\mathrm{dB})$.

\begin{tabular}{|c|c|c|c|c|c|c|c|}
\hline \multirow[t]{2}{*}{ Local } & \multicolumn{3}{|c|}{ Medição } & \multicolumn{3}{|c|}{ Situação (Adequado - A; Inadequado - I) } & \multirow[t]{2}{*}{$\begin{array}{c}\text { RECOMENDAÇÃ̃O } \\
\text { NBR 10152/1987 }\end{array}$} \\
\hline & Manhã & Tarde & Noite & Manhã & Tarde & Noite & \\
\hline Ponto A & $51.6 \mathrm{~dB}$ & $49.3 \mathrm{~dB}$ & $52 \mathrm{~dB}$ & I & $\mathrm{I}$ & I & \multirow{3}{*}{$30-45 \mathrm{~dB}$} \\
\hline Ponto B & $49.9 \mathrm{~dB}$ & $50.2 \mathrm{~dB}$ & $50.7 \mathrm{~dB}$ & $\mathrm{I}$ & I & I & \\
\hline Ponto C & $53.6 \mathrm{~dB}$ & $51.8 \mathrm{~dB}$ & $52.4 \mathrm{~dB}$ & $\mathrm{I}$ & $\mathrm{I}$ & A & \\
\hline
\end{tabular}




\section{JOP 21 DESIGN

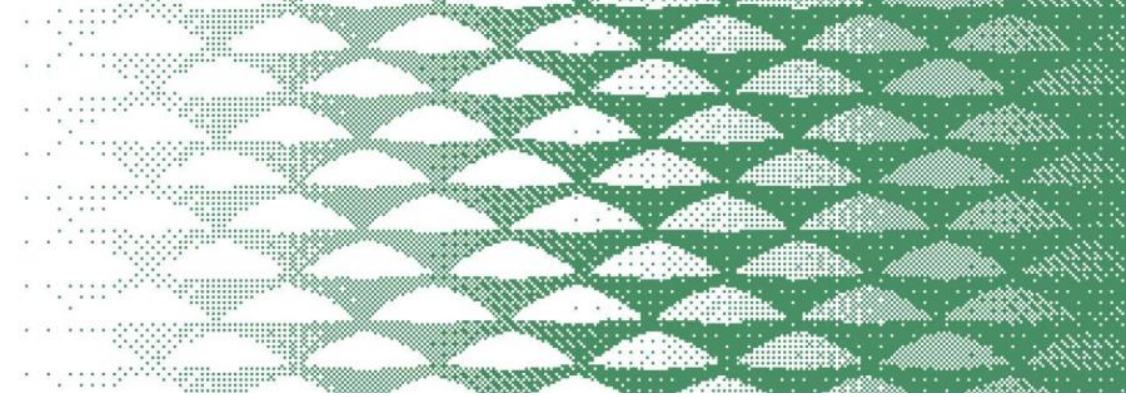

Fonte: Os autores (2021)

No que diz respeito à etapa da Avaliação do Ambiente em Uso, verificou-se a usabilidade do espaço, percebendo os usuários e suas posturas corporais. A Biblioteca oferece algumas condições de acessibilidade, usufruindo de piso nivelado com o exterior no acesso principal, dimensões adequadas na porta de acesso, duas cabines exclusivas para cadeirantes e circulação interna variável entre $0.90 \mathrm{~m}$ e 1.08 m de largura, compatível com o mínimo estabelecido pela NBR 9050/2015, apesar de que o local não possui espaço para rotação adequada das cadeiras de rodas, obrigando os usuários a transitarem em linha reta para frente ou voltando de costas. Além disso, muitas das dimensões do mobiliário encontraram-se em desacordo com recomendações de Panero e Zelnik (2016), dificultando que o cadeirante execute algumas atividades, a exemplo das estantes do acervo que, devido à sua altura, as prateleiras na porção superior não são acessíveis a estes usuários. Além disso, as cabines de estudo possuem tomadas posicionadas no rodapé da cabine, dificultando o seu alcance manual do indivíduo cadeirante, conforme Figura 4.

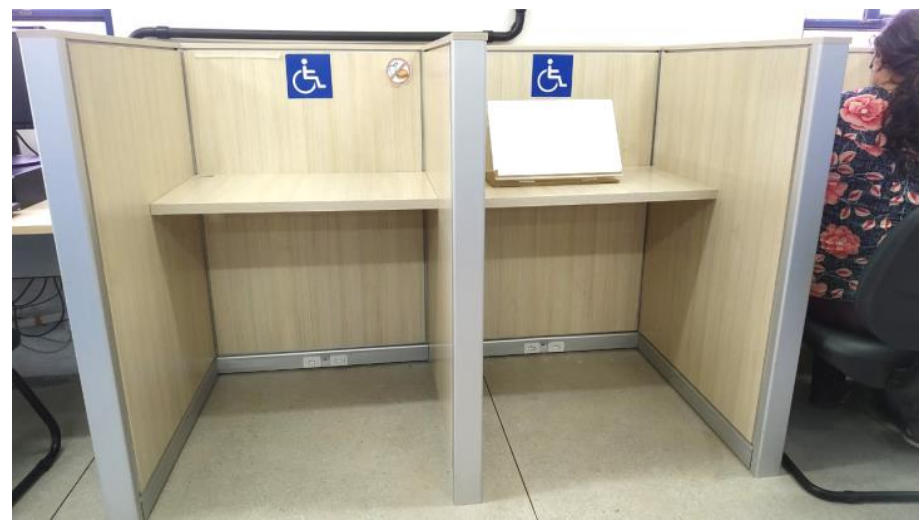

Figura 4 - Cabines para estudo de indivíduos cadeirantes.

Fonte: Os autores (2021)

Quanto ao leiaute, observaram-se obstáculos limitantes da circulação, (outros usuários, pilares, mobiliário, equipamentos). Neste ponto, avaliou-se o fluxo de circulação de cadeirantes no ambiente, através da inserção de modelos antropométricos em cadeiras de roda na planta baixa do ambiente, como apresenta o Figura 5.

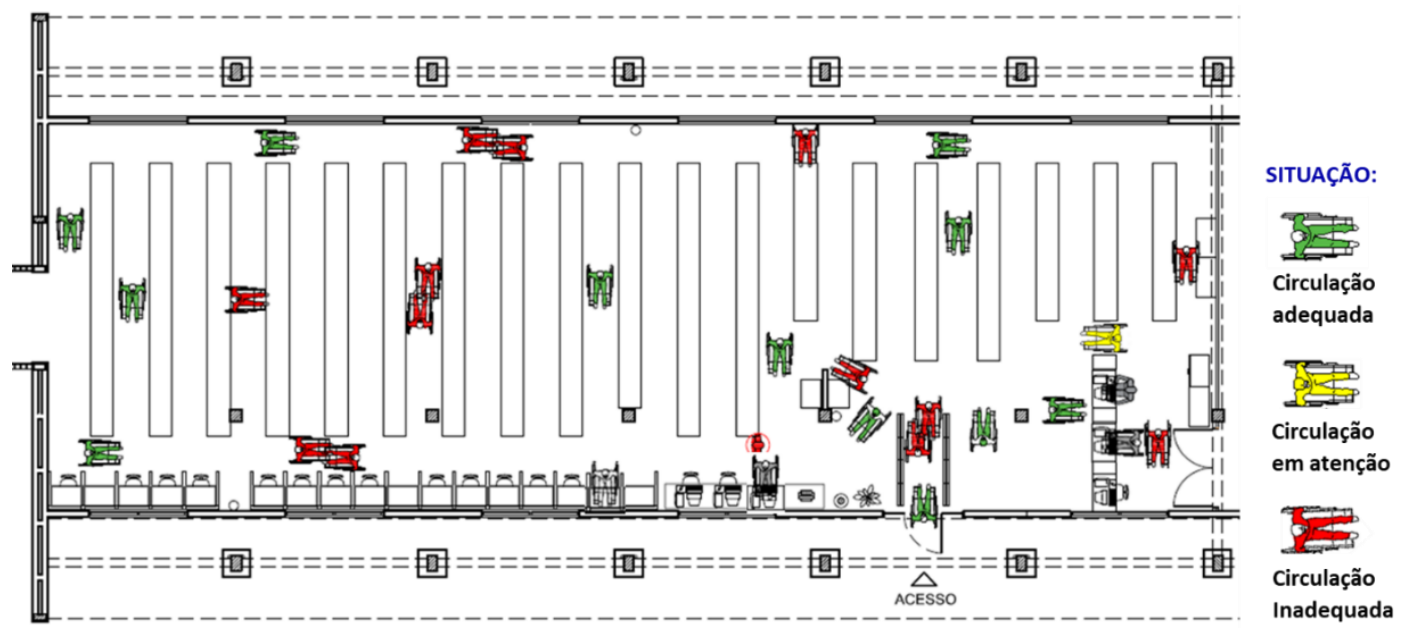




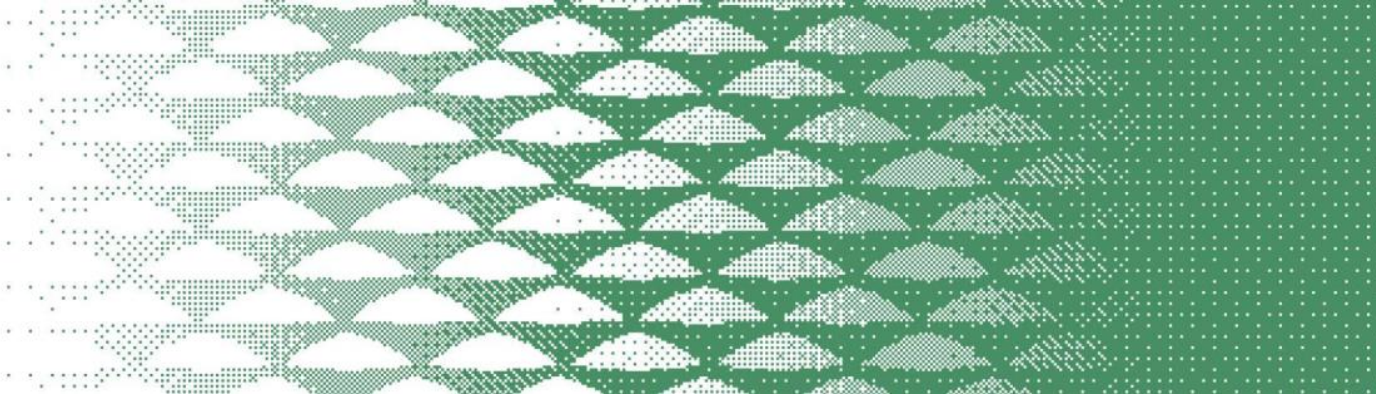

Diante disso, foi possível elaborar recomendações ergonômicas importantes para o ambiente, conforme a Tabela 04:

Tabela 4 - Recomendações propostas.

\begin{tabular}{|l|}
\hline - Reposicionar e substituir a porta de acesso, por um modelo em corrediça e maior; \\
\hline - Construir uma saída de emergência com portas com acessibilidade; \\
\hline - Realocar um dos pares do sensor de segurança para o lado externo da porta de acesso; \\
\hline - Reorganizar as estantes: as grandes devem ser conectadas e formarem corredores; as menores devem \\
ser alinhadas com os pilares; e 1 média deve ser retirada e enviada ao depósito da universidade; \\
\hline - Os 4 primeiros corredores devem apresentar 1,50m de largura e o $5^{\circ}$ corredor, ao sul do prédio, deve \\
apresentar 1,30m de largura; \\
\hline - Incluir estantes nos espaços vagos, inclusive abaixo e ao lado das janelas ao norte do prédio; \\
\hline - Alterar altura de fixação das tomadas para pontos com altura confortável ao acesso manual dos \\
usuários cadeirantes; \\
\hline - Reformar as mesas das cabines, oferecendo mesas de alturas de tampo distintas para adequação de \\
usuários de várias dimensões corporais; \\
\hline - Instalar cortinas persianas nas janelas das áreas de atendimento, estudo e consulta eletrônica, para \\
controle da incidência solar sobre o usuário e computadores; \\
\hline - Aplicar revestimentos nas paredes, os quais diminuam a reverberação do som; \\
\hline -Aplicar uma nova paleta de cores equilibrada que promova tranquilidade, entusiasmo e iluminação. \\
\hline
\end{tabular}
Fonte: Os autores (2021)

Diante das recomendações propostas, uma sugestão de novo leiaute foi concebida e apresentada à instituição de ensino (Figura 7).

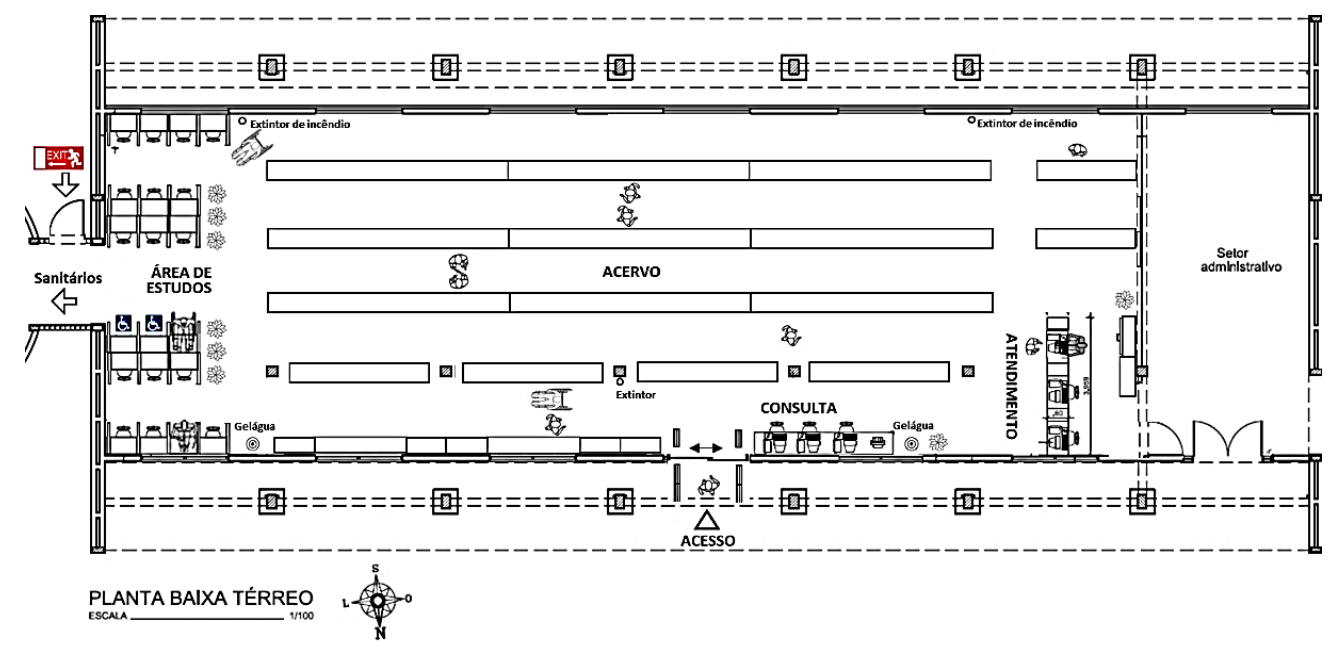

Figura 7 - Sugestão de novo leiaute.

Fonte: Os autores (2021)

\section{Conclusões}

O corrente estudo nos faz refletir se o processo de disseminação de novos campi não considera o usuário cadeirante ou os impactos decorrentes da relação deste usuário com o ambiente construído, em razão de uma rápida instalação de edificações. $\mathrm{O}$ estudo apontou falhas como a impossibilidade de $\mathrm{o}$ cadeirante transitar nos corredores estreitos ou até mesmo dificuldades de ler devido ao ofuscamento, 
atividades básicas neste tipo de ambiente.

As diversas inadequações detectadas na investigação revelam a necessidade de se sugerir que o governo brasileiro recomende que as propostas de novas edificações universitárias federais considerem o ser humano como centro do projeto. A partir de então se recomendaria que os centros acadêmicos de cada campus pudessem estabelecer uma comissão de avaliação ergonômica das instalações, a qual ficaria responsável por verificar possíveis inadequações tanto em fase projetual, como nos espaços já edificados. Para tanto, a metodologia MEAC se revelou bastante eficaz, conduzindo a equipe de pesquisa à identificação de falhas nas diversas áreas que as atividades envolviam.

Accessibility in public universities: a case study of a library

Abstract: The diffusion of public universities in Brazil, allied to the technologies of precast civil engineering systems, has made possible the rapid construction of university centers, including libraries, which can lead to accessibility problems in these spaces. The article analyzes the accessibility of a newly built library at a public university in the Brazilian Northeast, using the Ergonomic Methodology for the Built Environment (MEAC). The investigation pointed out several inconsistencies with regard to accessibility and some other additional factors, which made it possible to elaborate a series of ergonomic recommendations directed to the library with a focus on the accessibility of wheelchair users.

Keywords: acessibility; library; public university.

\section{Referências bibliográficas}

BRITO, Erilze Maria da Silva. Avaliação dos aspectos físicos, tecnológicos e atitudinais direcionados aos usuários com deficiência visual: estudo em uma biblioteca universitária. Dissertação de Mestrado, PPGE/UFPE - Ergonomia. Recife-PE, 2018.

CAPRI, Daniela; DOS SANTOS BAHIA, Eliana Maria; LUIZ PINTO, Adilson. Ergonomia: estudo de caso em biblioteca universitária. Biblios, núm. 48, 2012, pp. 41-54.

MENDES, L. H. D.; BERGIANTE, Níssia Carvalho Rosa. Promoção da qualidade de vida no trabalho em bibliotecas universitárias através da aplicação da ergonomia. Brazilian Journal of Development, Vol 4, No 6, 2018.

PANERO, J.; ZELNIK, M. Dimensionamento humano para espaços interiores. 1. Ed. Barcelona: Gustavo Gilli, SL, 2016.

TASSA, Chadia Mohamad; BRAGA, Rogério de Souza; MOTTER, Arlete Ana. Análise ergonômica do trabalho no atendimento ao público de uma biblioteca universitária. Cadernos de educação, saúde e fisioterapia. v. 5, n. 10. 2018.

VASCONCELOS, Christianne Soares Falcão; VILLAROUCO, Vilma; SOARES, Marcelo. Avaliação Ergonômica do Ambiente Construído: Estudo de caso em uma biblioteca universitária. Ação Ergonômica, v.4, n.1, 2009.

VILLAROUCO, V. 0 ambiente está adequado? Anais do ENEAC 2007: I Encontro Nacional de Ergonomia do Ambiente Construído e II Seminário Brasileiro de Acessibilidade Integral. Recife, 2007. 
WELLICHAN, Danielle S. P.; SANTOS, Marcella G. F. Qualidade de vida em bibliotecas: como a ergonomia e a ginástica laboral contribuem para rotinas mais saudáveis nas bibliotecas universitárias. Revista ACB: Biblioteconomia em Santa Catarina, ISSN 1414-0594, Vol. 22, №. 3, 2017, págs. 611625. 